\section{Comment on Roper's discussion of the language and generality of schedule-induced behavior}

\author{
CORA LEE WETHERINGTON \\ University of North Carolina at Charlotte, \\ Charlotte, North Carolina \\ and

\section{AARON J. BROWNSTEIN \\ University of North Carolina at Greensboro,} \\ Greensboro, North Carolina
}

Excessive water intake in rats fed under an intermittent food schedule was first reported by Falk (1961), who subsequently termed the phenomenon "schedule-induced polydipsia" (Falk, 1964). In 1971, Falk cited a number of instances of scheduleinduced behavior, pointed out correspondencies among them, and argued for "the recognition of the new class of behavior termed adjunctive" (p. 578). One of the defining features of adjunctive behavior was excessiveness: "Adjunctive behavior is a stable increase in behavior . . . [it] is behavior maintained at high probability" (p. 586). Since Falk's 1971 paper, the terms "schedule-induced behavior" and "adjunctive behavior" have been used interchangeably. In 1977, Staddon introduced the term "facultative behavior" to refer to behavior which lacks the characteristic of excessiveness but which otherwise would be termed adjunctive or schedule-induced.

We found two aspects of Roper's (1981) recent paper to be particularly illuminating for this general area of research. First, we applaud Roper for his effort "to suggest a criterion whereby induction can be recognized experimentally" (p. 434). Over the past 20 years, a large research effort has been devoted to the study of schedule-induced behavior despite the lack of a clear consensus on the proper criterion for determining whether a behavior is schedule-induced. Roper argues, and we agree, that the term "scheduleinduced" should be reserved for those behaviors whose occurrence is higher during an intermittent food condition than during both a massed and an extinction (more technically, no food) condition. The logic is as follows. The no-food baseline alone is insufficient because any difference between that condition and an intermittent food condition could be due to food or to intermittence. The massed baseline alone is insufficient, because the occurrence of a behavior may be greater under intermittent food but

The first author's mailing address is: Department of Psychology, University of North Carolina, Charlotte, North Carolina 28223. still greater under the no-food condition. Thus, two types of increases in behavior can be identified when food is scheduled intermittently, but the label "schedule induction" is appropriate only when both increases are evident.

A second noteworthy aspect of Roper's paper is his suggestion of separate usage of the terms "scheduleinduced behavior" and "adjunctive behavior." $\mathrm{He}$ suggests a more restricted usage of the term "scheduleinduced behavior" and a broader usage of the term "adjunctive behavior." He suggests that the term "adjunctive behavior" include both types of increases associated with intermittent schedules, and he selects the term "facultative" (Staddon, 1977) to refer to noninduced increases. Although the terms "schedule-induced" and "adjunctive" have been used interchangeably in the past, this shift in terminology offers two important advantages. First, it emphasizes that all behavior that occurs as an adjunct to a schedule may not be induced by the schedule. Second, it emphasizes that all behavior that occurs at a higher rate during intermittent food than during massed food may not be schedule-induced.

Despite these two contributions which Roper's paper makes, there are aspects of the paper that are directly, or by implication, problematic.

It is not clear what is meant by "a most suitable measure" of schedule-induced behavior and why rate is chosen. We share Roper's concern about the various measures that have been used to assess schedule-induction. It appears, however, that the problem lies not in the measures per se, but in the conditions under which they have been used. For example, intake has been examined with session time being permitted to vary and hence opportunity to drink being unequal. One solution, under such circumstances, would be to correct for varying periods of opportunity by dividing intake by the session time, that is, computing an ingestion rate. Although Roper's choice of rate seems to be based on this logic, it is not clear why ingestion rate is more ideal than other measures which would correct for opportunity-for example, total time spent drinking and even number of bouts (intervals with a drink) of induced behavior could be corrected for differential interruption of ongoing activity by programming some event other than food. If the various corrected measures covary, then there is no basis for claiming rate as the ideal measure. If the various corrected measures do not covary, then the choice of rate as the ideal measure must be justified on grounds other than its providing a correction for unequal opportunity to drink. Roper's choice of rate as the ideal measure of induction is especially puzzling in view of his contention that in order to determine the occurrence of 
induction the intermittent and baseline conditions should be of equal duration and an equal number of reinforcers should be provided in the intermittent and massed conditions. Under these circumstances, a simple intake measure is equivalent to a rate measure.

If the choice of rate is not primarily for correction purposes, then some further justification is necessary for the choice of rate as the most suitable measure of schedule induction. Since there is no consensus on the most suitable measure of behavior in general, it is not clear why rate is the best measure of scheduleinduced behavior. Assuming that Roper could establish the necessity of using rate change as a measure of induction, the discussion of the Roper and Crossland (1982) research leaves unclear whether a rate change is sufficient. Roper and Crossland (1982) reported that wood-chewing met Roper's rate-change criteria for induction. Roper (1981) considered the effects "unreliable," however, because, in comparison with schedule-induced drinking, "it occurs in a relatively small proportion of interreinforcement intervals, tends to decline within the session, and fails to appear at all in some subjects" (p. 438). While we are inclined to consider the number of subjects in which a phenomenon occurs as a measure of reliability, the other measures reflect less about reliability and more about molecular characteristics accompanying the rate change effect. Roper appears to have weighted the first two characteristics heavily in his conclusion that wood-chewing induction was unreliable. Such consideration seems to imply that rate change is a necessary, but not sufficient, measure of schedule induction.

Finally, the use of rate as the most appropriate measure of schedule induction is predicated on the assumption that rates from unequal observation periods may be compared directly. In view of recent evidence that such comparability does not always exist (Reid \& Staddon, 1982), and as long as opportunity is equally provided in all experimental and control conditions, it seems most appropriate to make use of measures that are more direct than rate. Furthermore, Roper appears to make the assumption that rate should be based upon the entire session length. This assumption may not be entirely appropriate if, for example, schedule induction is modulated through time allocation.

An additional concern with reliance upon overall rate, or any other corrected measure, to define induction is that other important sources of control are overlooked, particularly temporal control. Wetherington and Brownstein (1979) reported that scheduling water in no way induced eating, but clearly produced temporal control of eating (also, see Roper, 1980). Several studies (e.g., Anderson \& Shettleworth, 1977; Killeen, 1975; Staddon \&
Simmelhag, 1971) have indicated that regular presentation of food generates temporal control over ongoing behavior. Indeed, temporal control of behavior may be a more fundamental measure than rate.

A second aspect of Roper's paper that may be problematic is his suggestions regarding new usage of the term "adjunctive behavior." Since "scheduleinduced" and "adjunctive behavior" have been used synonymously, we feel that it would be confusing to use the term "adjunctive-behavior" as a higher order category that includes schedule-induced behavior as a subcategory. Elsewhere (Wetherington \& Brownstein, 1979), we have used the term "schedule-modulated" as a more comprehensive descriptive label to include schedule-induced (excessive) behavior (or adjunctive behavior) as well as noninduced behaviors over which the schedule generates temporal control. We chose to leave this latter category unlabeled in order to allow for the possibility that it might contain more than one class of effects, for example, schedule suppression. Within this framework, schedule-induced behavior and adjunctive behavior maintain their prior synonymous usage, but the distinction Roper wishes to emphasize by dissociating them is nonetheless achieved. For the non-schedule-induced subclass of schedule-modulated behavior, Roper has suggested the term "facultative" behavior. This term, however, is not theoretically neutral, and this may therefore be an unwise choice. Staddon's (1977) definition of facultative behavior specifies a theoretical relationship with schedule-induced behavior. We feel that an important distinction which Roper wishes to emphasize by labeling both categories of what we have called schedule-modulated behavior becomes complicated by theoretical issues associated with his choice of the term "facultative."

If Roper's contention that schedule-induced behavior is less general than previously believed is correct, the casual reader may incorrectly infer that there is less to explain. What still remains is a need for a comprehensive theory of what we have called schedule-modulated behavior (Wetherington \& Brownstein, 1979). Roper's review suggests that an induction mechanism explains less of this broad class of behavioral effects than was previously thought to be the case. Some additional mechanisms are clearly needed. One major theory has suggested competition as a mechanism to account for the occurrence of noninduced behavior (Staddon, 1977). In this view, noninduced behaviors rise and fall as they compete with induced behavior. However, if it is the case, as Roper contends, that only scheduling food will induce behavior, then the behavioral effects accompanying scheduled events other than food are an enigma, since they can be neither the result of induction nor competition from induced behavior. Clearly, the mechanisms of induction and competi- 
tion are insufficient to account for noninduced schedule-modulated behavior if schedule-induced polydipsia is the only schedule-induced behavior. Roper's review serves to stimulate (induce?) concern for factors directly related to noninduced schedulemodulated behavior.

\section{REFERENCES}

Anderson, M. C., \& Shetrteworth, S. J. Behavioral adaptation to fixed-interval and fixed-time food delivery in golden hamsters. Journal of the Experimental Analysis of Behavior, $1977,25,33-49$.

FALK, J. L. Production of polydipsia in normal rats by an intermittent food schedule. Science, 1961, 133, 195-196.

FALK, J. L. Studies on schedule-induced polydipsia. In M. J. Wayner (Ed.), Thirst: First International Symposium on Thirst in the Regulation of Body Water. New York: Pergamon, 1964.

FALK, J. L. The nature and determinants of adjunctive behavior. Physiology \& Behavior, 1971, 6, 577-588.

Killeev, P. On the temporal control of behavior. Psychological Review, 1975, 82, 89-115.
REID, A. K., \& Staddon, J. E. R. Schedule-induced drinking: Elicitation, anticipation, or behavioral interaction? Journal of the Experimental Analysis of Behavior, 1982, 38, 1-18.

ROPE R, T. J. Behavior of rats during self-initiated pauses in feeding and drinking, and during periodic response-independent delivery of food and water. Quarterly Journal of Experimental Psychology, 1980, 32, 459-472.

ROPER, T. J. What is meant by the term "schedule-induced," and how general is schedule induction? Animal Learning \& Behavior, 1981, 4, 433-440.

Roper, T. J., \& Crossland, G. Schedule-induced wood-chewing in rats and its dependence on body weight. Animal Learning \& Behavior, 1982, 10, 65-71.

Staddon, J. E. R. Schedule-induced behavior. In W. K. Honig \& J. E. R. Staddon (Eds.), Handbook of operant behavior. Englewood: Prentice-Hall, 1977.

Staddon, J. E. R., \& Simmelhao, V. L. The "superstition" experiment: A re-evaluation of its implications for the principles of adaptive behavior. Psychological Review, 1971, 78, 3-43.

Wetherinaton, C. L., \& Brownstein, A. J. Schedule control of eating by fixed-time schedules of water presentation. Animal Learning \& Behavior, 1979, 7, 38-40.

(Manuscript received May 27, 1982; revision accepted for publication August 4, 1982.) 